\title{
Simulation of laminar bimorph piezoelectric microactuators with application in miniaturized robots
}

\section{Simulation of laminar bimorph piezoelectric microactuators with application in miniaturized robots}

Juan Alfaro Barrantes'

Paola Vega Castillo²

Marta Vílchez Monge 3

Marco Rodríguez Montero ${ }^{4}$

Fecha de recepción: 20 de enero del 2012

Fecha de aprobación: 19 de marzo del 2012

Alfaro, J; Vega, P; Víchez, M; Rodríguez, M. Simulation of laminar bimorph piezoelectric microactuators with application in miniaturized robots.

Tecnología en Marcha. Vol. 25, № 5. Pág I I 6-I 23.

I Ingeniero en Electrónica. Tecnológico de Costa Rica, Escuela de Ingeniería Electrónica. Teléfono: 8820-7| 35.

Correo electrónico: analbal I@gmail.com

2 Doctora en Microelectrónica. Tecnológico de Costa Rica, Escuela de Ingeniería Electrónica. Teléfono: 2550-9248. Correo electrónico: pvega@itcr.ac.cr

3 Física. Tecnológico de Costa Rica, Escuela de Física. Teléfono: 8992-7| 34. Correo electrónico: mvilchez@itcr.ac.cr

4 Ingeniero en Electrónica. Tecnológico de Costa Rica, Escuela de Electrónica. Teléfono: 8853-0764.

Correo electrónico: marco.rodrim@gmail.com

Este artículo cuenta con el aval de la Vicerrectoría de Investigación y Extensión del Tecnológico de Costa Rica 


\section{Resumen}

Para implementar robots miniaturizados debe evaluarse las diferentes posibilidades de actuación electromecánica a la microescala, de acuerdo con la función que el actuador cumplirá en el robot, el tamaño, la resistencia mecánica,la deformación, la resolución, la tensión de alimentación, la energía y los grados de libertad requeridos. Los actuadores piezoeléctricos se consideran como una de las posibilidades más factibles para incorporaractuadores en robots miniaturizados. Este artículo presenta una descripción de la actuación piezoeléctrica y la evaluación de un actuador de microposicionamiento $x-y$ para un robot miniaturizado, utilizando COMSOL Multiphysics.

\section{Palabras clave}

Sistemas microelectromecánicos, MEMS, microactuadores, actuador laminar bimorfo, método de elementos finitos, simulación, robot miniaturizado.

\begin{abstract}
In order to implement miniaturized robots different possibilities for electromechanical actuation at the microscale must be evaluated according to their function on the robot, as well as, size, mechanical strength and deformation, resolution, power supply, energy and degrees of freedom required. The piezoelectric actuators are among the most suitable possibilities to incorporate microactuators in miniaturized robots. This article presents an overview of piezoelectric actuation and the evaluation of a simple $x-y$ micropositioning actuator for a miniaturized robot using COMSOL Multiphysics.
\end{abstract}

\section{Key words}

Microelectromechanical systems, MEMS, microactuator, laminar bimorph actuator, Finite Element Method, simulation, miniaturized robot.

\section{Introduction}

From the mechanical point of view, the design of miniaturized robots faces a need of balance between functionality and size. The use of microelectromechanical systems (MEMS) with increasing degrees of freedom leads to increased volume, power consumption, supply voltage, actuation current and complexity. In addition to that, the designer must deal with the equilibrium between high precision and large displacement.

The scaling of physical effects is a key aspect in choosing a MEMS actuator. Effects commonly analysed in the meso and macroscale may not be feasible for MEMS, such as the case of magnetic induction. Selection of materials and actuation effects are affected by the environment operation's characteristics. In vacuum environments the power consumption of the actuator is an important issue, since conventional cooling mechanisms such as convection are not available. Thermal actuators are not suitable for those environments since returning to the rest position implies a decrease in the temperature of the actuator.

Fabrication aspects must also be considered, specially cost and equipment for patterning, deposition, etching and clean room facilities available to implement a specific geometry and the required materials. Fabrication processes for commercial and academic prototyping are also an option to decrease cost. However, the designer must adapt the design to the specific materials and process characteristics offered by each vendor.

Piezoelectric actuation is one of the most effective ways to incorporate microactuators in miniaturized robots, due to their low actuation voltage, low power consumption, ease of control and response time. Moreover, the actuator's displacement can be increased by adding electroactive layers to it. In the following sections, a brief overview of piezoelectric actuation is presented, as well as simulations of a laminar bimorph piezoelectric actuator with application in a simple $x-y$ positioning microactuator for a miniaturized robot.

\section{Overview of Piezoelectric Actuation and Modeling}

In an elastic body without applied electric field, the stress $T$ and the deformation $S$ are related by $\mathrm{T}=c \mathrm{~S} \quad(1)$ 
Where $c$ is the material's stiffness [I]. For piezoelectric materials, the electrical and mechanical constitutive equations are coupled. In case of actuators, an applied electric field aligns the internal dipoles, causing stress in the material. This is known as the inverse piezoelectric effect.

The design of piezoelectric systems depends on the coupling modes, that is, the non-zero piezoelectric coupling matrix elements [I]. In case of actuators, the strain of a piezoelectric material as a function of the applied electric field is given by equation 2 .

$\mathrm{S}=S^{E} \mathrm{~T}+d^{t} \mathrm{E} \quad(2)$

Where $\mathbf{S}$ is the strain, $\mathbf{T}$ is the stress measured in $\mathrm{N} / \mathrm{m}^{2}$ for a constant electric field with constant stress, $s$ is the compliance matrix and the superscript $E$ indicates zero electric field, $d^{t}$ is the converse piezoelectric effect matrix, that is, the transposed piezoelectric coupling coefficient matrix.

Three main actuation modes are available to implement piezoelectric actuators: thickness mode ( $d_{33}$ coupling), shear mode ( $d_{15}$ coupling) and in plane mode ( $d_{31}$ coupling).

In the shear mode the piezoelectric coupling constant $d_{15}=d_{24}$ dominates. The electric field is applied perpendicularly to the polarization direction.

The thickness mode is used for stack actuators. On the other hand, standard and bimorph laminar actuators relies on the in plane mode. In the in plane mode, $d_{31}$ is the dominant constant, and the direction of displacement is normal to the electric field. PZT materials are isotropic materials in the direction perpendicular to the direction of polarization $\left(\mathrm{d}_{32}=\mathrm{d}_{31}\right)$. In a laminar standard design, the displacement relates the applied voltage $\mathrm{V}_{0}$ with the piezoelectric layer thickness as follows [I]:

$\Delta=\frac{d_{31} V_{0} \cdot L}{a}$

where $d_{31}$ is the transverse piezoelectric coupling constant, $V_{0}$ is the applied voltage, $L$ is the actuator's length and $a$ is the total piezoelectric thickness of the actuator.

In this case, the actuator deforms perpendicularly to the polarization direction. In laminar bimorph designs, the actuator deforms in the direction of the electric field, thus combining the operating principle of the stack actuator and the coupling coefficient $\mathrm{d} 3 \mathrm{I}$ of the in plane mode.

As a first approximation, the displacement is given by equation $4[\mathrm{I}]$ and includes the square of the actuator's length $L$ and total thickness $a$, in comparison to equation 3 :

$\Delta=\frac{3 d_{31} V_{0} L^{2}}{2 a^{2}}$

The largest displacement and deformation occurs at the resonant frequency. This frequency is approximated by the following equation [2]

$f_{\text {res }}=\frac{K_{n} t_{a}}{\pi^{2}} \sqrt{\frac{Y_{a}}{12 \rho_{\text {eff }}}}$

where $t_{a}$ is the total thickness of the actuator, $Y_{a}$ is the Young's modulus of the piezoelectric material, $\rho_{\text {eff }}$ is the effective density of the actuator, $K_{n}$ is a constant in which the subscript " $n$ " represents the vibration mode $\left(K_{1}=3.52, K_{2}=22.0\right)$ and $L$ is the effective length of the actuator.

\section{Conception of the microactuator}

In order to incorporate the microactuator in the miniaturized robot, some requirements are needed:

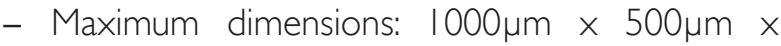
$500 \mu \mathrm{m}$

- Power consumption: lower than ImW

- Supply voltage: $3 \mathrm{~V}$

- Operation in dry, vacuum environments

- Precision: better than 50nm

The simulated actuator is a laminar bimorph actuator, and thus operates in the coupling mode $\mathrm{d}_{3}$. This type of actuator makes possible to achieve displacements larger than $0.1 \%$ of the actuator's length.

The piezoelectric used in this design is the PZT3203HD from Motorola. The geometry of the actuator is presented in figure I. It consists of two layers of piezoelectric material. Thin aluminum layer of $300 \mathrm{~nm}$ thickness in the outer layers serve as electrodes to contact the piezoelectric layers, and a third electrode is located between the piezoelectric layers. The operating voltage varies from 0 to $3 \mathrm{~V}$ which allows control of the displacement. The arrows show the direction the piezoelectric polarization. 


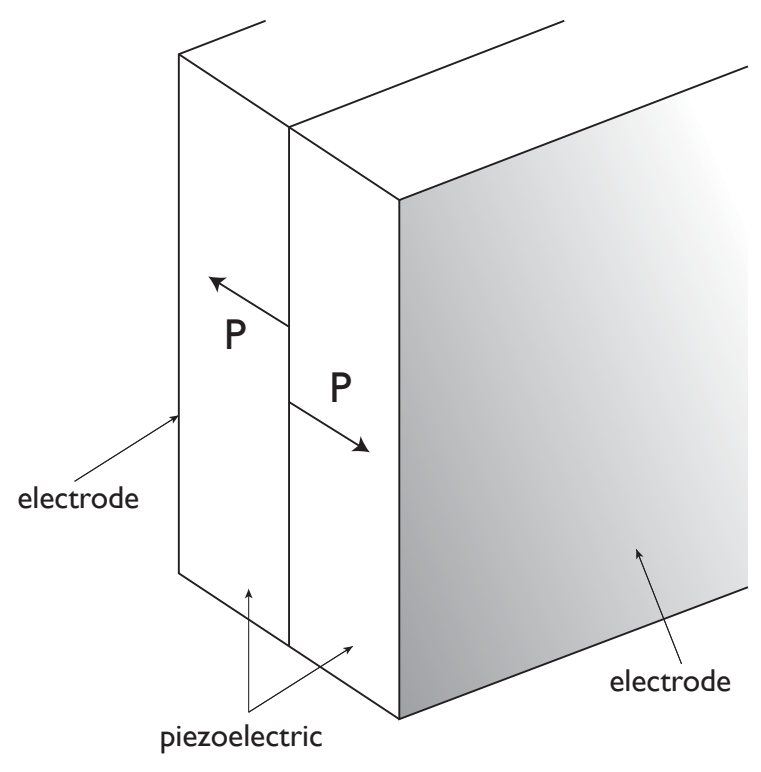

Figure I. Geometry of a laminar bimorph actuator.

The designed microactuator is required as the base for implementing a positioning system.

The simulated microactuator is based on two coupled laminar bimorph piezoelectric actuators to achieve positioning with two degrees of freedom, as shown in figure 2.

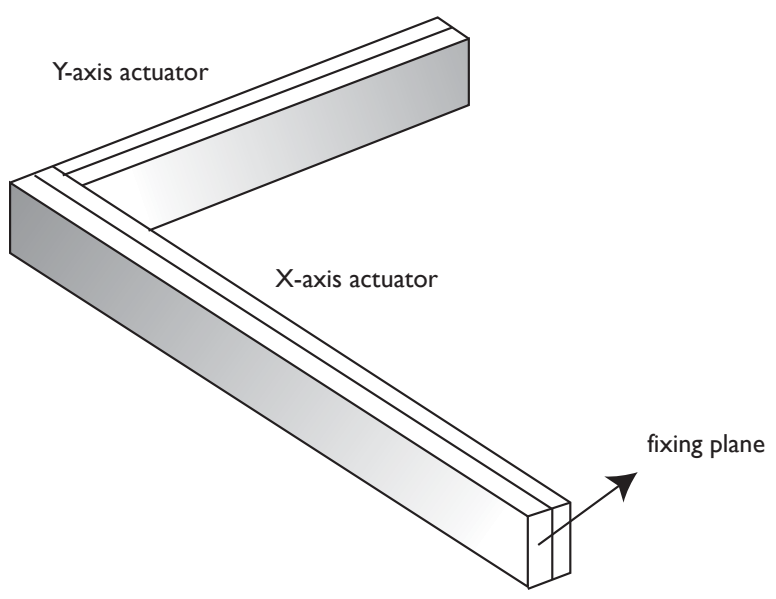

Figure 2. Proposed positioning microactuator.

For PZT3203HD, the coupling matriz yields [3]:

$d_{P Z T 3203 \mathrm{HD}}=\left(\begin{array}{cccccc}0 & 0 & 0 & 0 & 1000 & 0 \\ 0 & 0 & 0 & 1000 & 0 & 0 \\ -320 & -320 & 650 & 0 & 0 & 0\end{array}\right) 10^{-12} \mathrm{~m} / V$
The material's density is $7870 \mathrm{~kg} / \mathrm{m}^{3}$, the Young modulus $Y_{11}$ is $6.2 \times 10^{10} \mathrm{~N} / \mathrm{m}^{2}$ and the Poisson's ratio is 0.31 [4]. The dielectric constant $\mathrm{K}_{3}^{\top}$ is 3800 . The compliance matrix is given by $[3,4]$ :

$$
S_{E}=\left(\begin{array}{cccccc}
16.6 & -4.2 & -8.2 & 0 & 0 & 0 \\
-4.2 & 16.6 & -8.2 & 0 & 0 & 0 \\
-8.2 & -8.2 & 21 & 0 & 0 & 0 \\
0 & 0 & 0 & 52.4 & 0 & 0 \\
0 & 0 & 0 & 0 & 52.4 & 0 \\
0 & 0 & 0 & 0 & 0 & 52.4
\end{array}\right) \cdot 10^{-12} \frac{1}{P a}
$$

\section{Microactuator simulation}

The simulations were first done taking into consideration the piezo-solid model to obtain the mechanical displacement of the actuators.

The polarization direction of each layer must be considered in the simulation. The material's polarization must be oriented in the same direction as the electric field to obtain elongation in the desired direction. This is achieved by configuring the Coordinate System option for each subdomain, to correctly describe the piezoelectric polling, as shown in figure 1. The subdomains were assigned a coordinate system rotated $90^{\circ}$ about the axis of the actuator's length.

First, a single bimorph actuator was simulated using the following dimensions: $30 \mu \mathrm{m}$ height, $580 \mu \mathrm{m}$ length and two $5 \mu \mathrm{m}$-thick PZT layers. A displacement of $4.91 \mu \mathrm{m}$ was obtained when applying an actuation voltage of $3 \mathrm{~V}$. In order to determine the required length to operate at $1.5 \mathrm{~V}$, the actuator was simulated using $805 \mu \mathrm{m}$ length, obtaining a slighttly different displacement, that is, $4.73 \mu \mathrm{m}$.

Separate settings for each actuator of the $X Y$ micropositioner were required. The actuator along the $\mathrm{X}$ - axis provides displacement in the $Y$-direction and viceversa. A displacement of $4.13 \mu \mathrm{m}$ in the Y-direction was achieved with an actuator's length of $500 \mu \mathrm{m}, 30 \mu \mathrm{m}$ height and two $10 \mu \mathrm{m}$-thick PZT layers operated at IOV. On the other hand, $4.5 \mathrm{I} \mu \mathrm{m}$ in the X-direction was achieved with an actuator's length of $700 \mu \mathrm{m}, 30 \mu \mathrm{m}$ height and two $10 \mu \mathrm{m}$-thick PZT layers operated at IOV. When decreasing the layer thickness by two, similar displacements were achieved by operating at 3V. All simulations' results are summarized in table I. 
Table I. Maximum Actuator Displacement without Load

\begin{tabular}{|c|c|c|c|c|c|}
\hline \multirow[t]{2}{*}{ Configuration } & \multicolumn{2}{|c|}{ Length $(\mu \mathrm{m})$} & \multicolumn{2}{|c|}{$\begin{array}{c}\text { Displacement } \\
(\mu \mathrm{m})\end{array}$} & \multirow{2}{*}{$\begin{array}{l}\text { Thick-ness } \\
\qquad(\mu \mathrm{m})\end{array}$} \\
\hline & $x$ & $Y$ & $x$ & $\mathrm{Y}$ & \\
\hline $\begin{array}{l}\text { Bimorph } \\
\text { (at I.5V) }\end{array}$ & - & 805 & \pm 4.73 & - & 5 \\
\hline $\begin{array}{l}\text { Bimorph } \\
\text { (at 3V) }\end{array}$ & - & 580 & \pm 4.91 & - & 5 \\
\hline $\begin{array}{l}\text { Micropositioner } \\
\text { (at IOV) }\end{array}$ & 500 & 700 & \pm 4.51 & \pm 4.13 & 10 \\
\hline $\begin{array}{c}\text { Micropositioner } \\
\text { (at } 3 \mathrm{~V} \text { ) }\end{array}$ & 500 & 700 & \pm 5.39 & \pm 4.93 & 5 \\
\hline
\end{tabular}

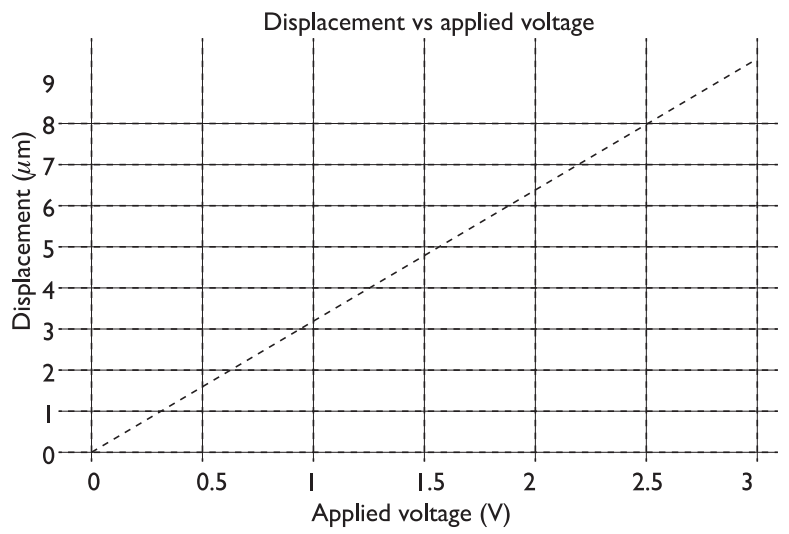

Figure 3.Laminar bimorph actuator displacement vs applied voltage at $\mathrm{L}=805 \mu \mathrm{m}$.

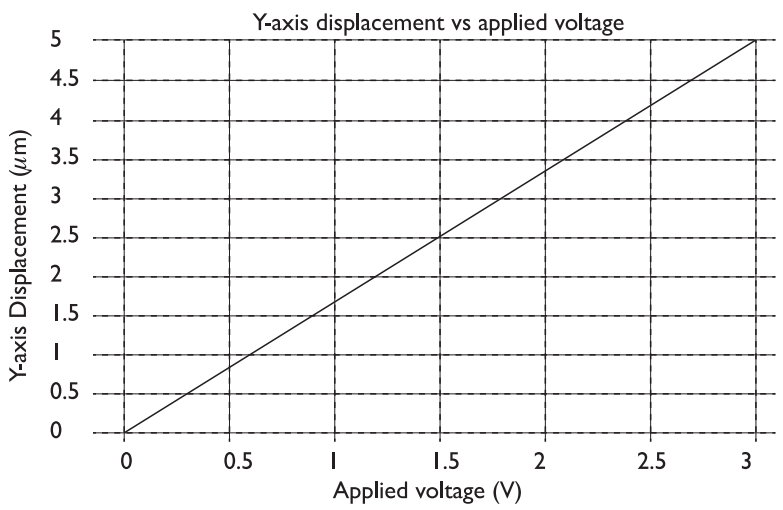

Figure 4. Y-axis displacement vs applied voltage for the thin micropositioner.

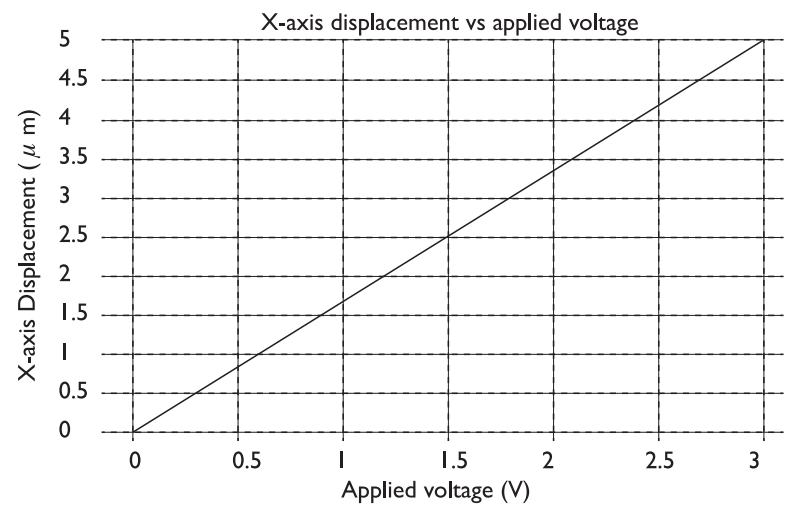

Figure 5. X-axis displacement vs applied voltage for the thin micropositioner.

For the short bimorph actuator, $163,6 \mathrm{~nm}$ displacement is obtained for each $100 \mathrm{mV}$ change at the applied voltage, whereas the long bimorph deforms $315,33 \mathrm{~nm}$ at the same applied voltage. The precision of the thick micropositioner is $41,3 \mathrm{~nm}$ in the Y-axis and $45,1 \mathrm{~nm}$ in the $X$-axis is obtained by applying $100 \mathrm{mV}$. For the thin micropositioner I 64nm in the $\mathrm{Y}$-axis and $180 \mathrm{~nm}$ in the $\mathrm{X}$-axis. This clearly shows the balance between larger displacement and precision. To achieve larger displacements, the actuator length can be increased or the piezoelectric layer thickness can be reduced. However, a larger actuator response displacements at a given voltage leads to larger resolution and thus less precision.

In order to consider the stress experienced by the actuators during displacement, a von Mises analysis was done. For ductile materials, failure results are shown when the von Mises stress is equal or higher than the yield stress of the material. In case of the piezoelectric microactuator this analysis allows calculation an equivalent stress in one direction which considers the stress experienced by the material in $x, y$ and $z$ directions. That is why this specific element constitutes an important criterion to design the actuator. The model solid stress-strain was added to the simulation to calculate the von Mises stress. The results are summarized in Table 2 .

As expected, table 2 shows that the maximum stress experienced both by the short bimorph actuator and the thick micropositioner. In case of the micropositioner, the region of maximum stress is located close to and at the bonding surface between the two bimorphs, as shown in figure 6. 

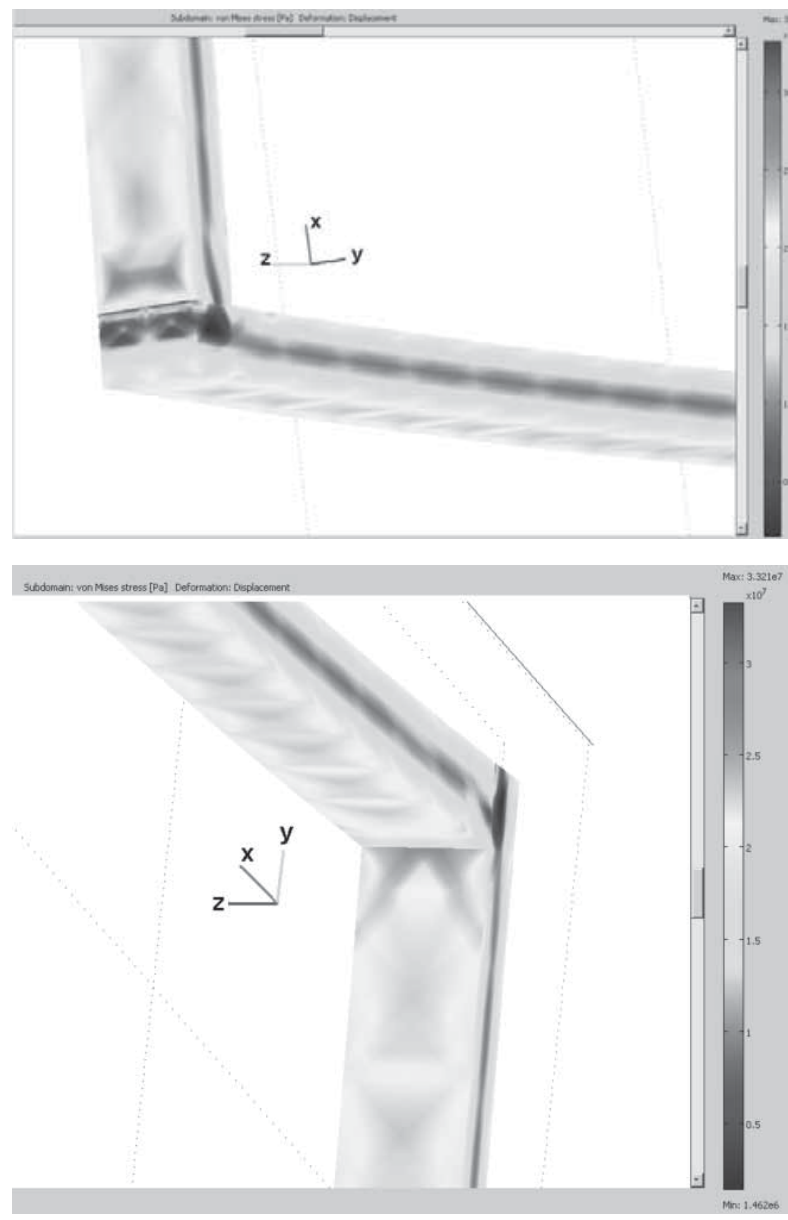

Figure 6. Regions of maximum Von Mises stress for the thick micropositioner.

Besides stress considerations, operating frequency of piezoelectric actuators must be taken into account. For some cases, it is desirable to operate close to resonance, such as in case of locomotion systems or load conveyors. However, resonant frequencies must be avoided in micropositioning applications. Figure 7 shows the frequency response of the laminar bimorph actuator at $L=805 \mu \mathrm{m}$ in the vicitiny of the resonant frequency. The operating voltage is $1.5 \mathrm{~V}$.

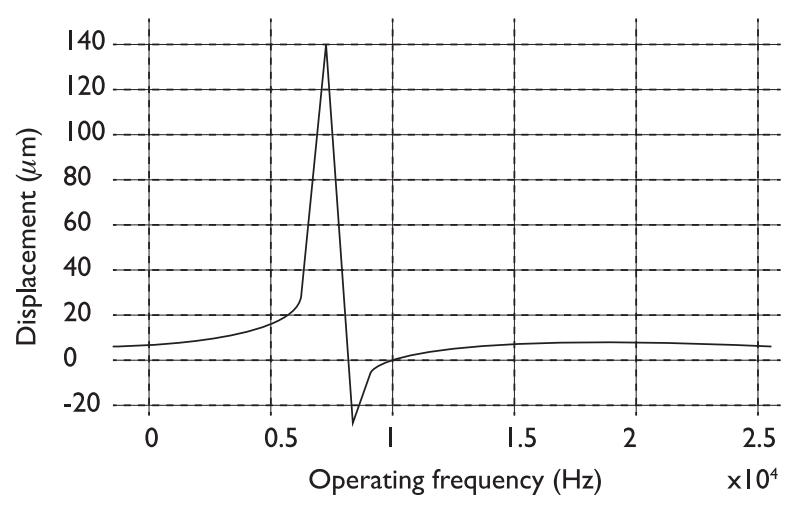

Figure 7. X-axis displacement vs frequency for the laminar bimorph actuator at $L=805 \mu \mathrm{m}$.

On the other hand, for $\mathrm{L}=580 \mu \mathrm{m}$ bimorph actuator the first resonant frequency is $13836 \mathrm{~Hz}$, and the actuator exhibits a total displacement of $192.6 \mu \mathrm{m}$. This is illustrated in figure 8 . The behavior for the second resonant frequency $86579 \mathrm{~Hz}$ is shown in figure 9. It can be observed the actuator deflects both in the $x$ and $z$ directions that at this frequency.

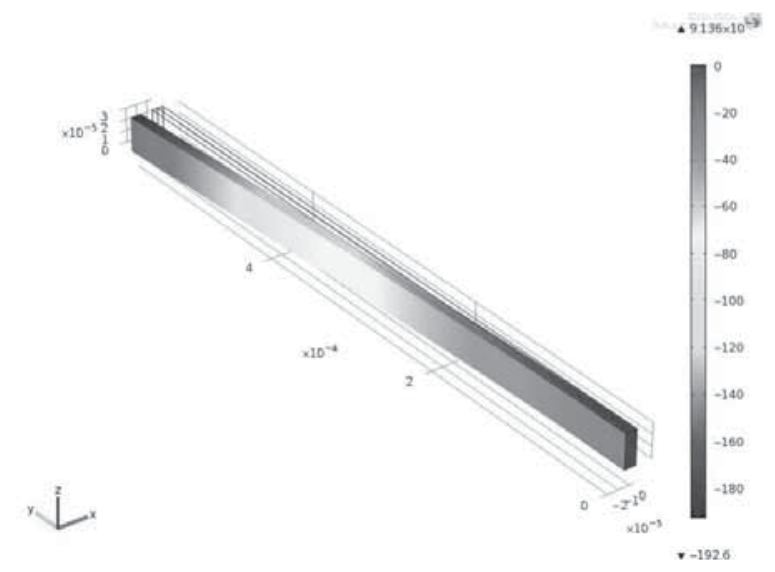

Figure 8. Behavior of laminar bimorph actuator at the first resonant frequency for $L=580 \mu \mathrm{m}$.

Table 2.Von Mises Stress without Load

\begin{tabular}{|c|c|c|c|}
\hline \multirow{2}{*}{ Configuration } & \multicolumn{2}{|c|}{ Von Mises Stress } & Actuator Thickness \\
& Minimum $(\mathrm{Pa})$ & Maximum $(\mathrm{Pa})$ & 5 \\
\hline Bimorph (at 1.5V) & $9.6 \times 10^{5}$ & $5.8 \times 10^{7}$ & 5 \\
\hline Bimorph (at 3V) & $1.7 \times 10^{6}$ & $1.2 \times 10^{8}$ & 10 \\
\hline Micropositioner (at IOV) & $1.5 \times 10^{6}$ & $3.3 \times 10^{7}$ & 5 \\
\hline Micropositioner (at 3V) & $4.1 \times 10^{5}$ & $1.9 \times 10^{7}$ & \multirow{2}{*}{} \\
\hline
\end{tabular}




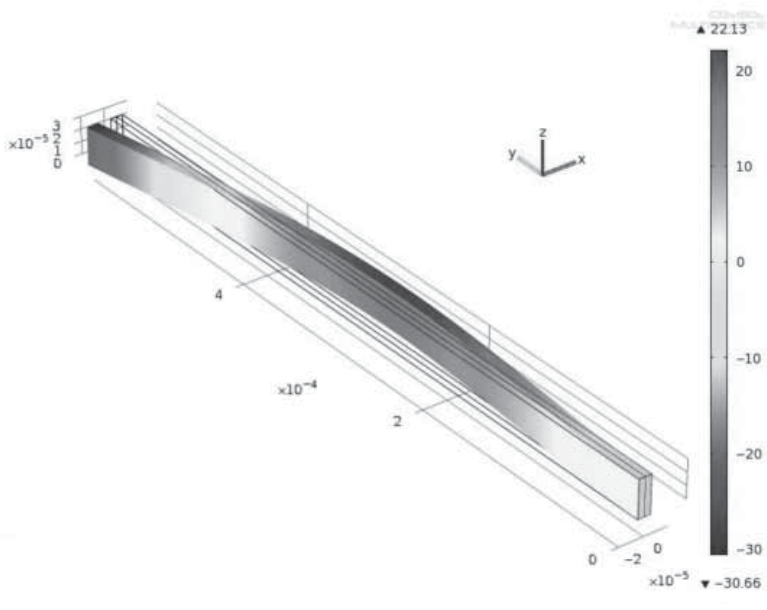

Figure 9. Deformation of laminar bimorph actuator at the second resonant frequency for $L=580 \mu \mathrm{m}$.

For the thick micropositioner operating at IOV the value of first eigenfrequency is located at $8390 \mathrm{~Hz}$. The displacement in the $x$ and $y$ axes in resonance is presented in figures 10 and $\mathrm{I}$, respectively. In case of the thin micropositioner operating at $3 \mathrm{~V}$, the first eigenfrequency is located at $4281.67 \mathrm{~Hz}$.

Calculated power consumption of the bimorph microactuators operating at $10 \mathrm{kHz}$ at is $4.44 \mathrm{~mW}$ for the short bimorph operating at $3 \mathrm{~V}$. Power decreases to $3.08 \mathrm{~mW}$ for the long bimorph that operates at I.5V. Comparing these two values, power consumption is $9,3 \%$ higher for the short bimorph, but the actuator's length is $28 \%$ shorter. It means that power does not decrease significantly as to

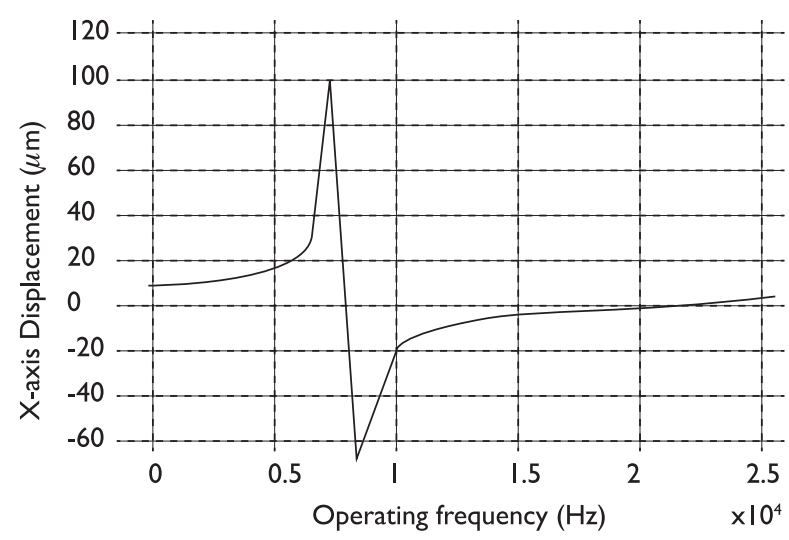

Figure 10. X-axis displacement vs frequency for the thick micropositioner. justify the increase in length, and is the predominant criterion to implement the short rather than the long bimorph.

For the micropositioner, power calculations have shown that the thin micropositioner would consume $18,4 \mathrm{~mW}$ when both bimorphs operate at $10 \mathrm{kHz}$ and $3 \mathrm{~V}$. Increasing the piezoelectric thickness from $5 \mathrm{~mm}$ to $10 \mathrm{~mm}$, increased power consumption in a factor of 5,54 that is, reaching $102 \mathrm{~mW}$ at IOV, since the increased thickness requires higher electric fields. Higher operating voltages greatly increase power consumption; power is proportional to the square of the supply voltage. Therefore, in spite of achieving similar displacements, the piezoelectric thickness is a critical factor in implementing a microactuator.

\section{Conclusions}

In comparison with other actuators presented in literature $[5,6]$, the designed actuator is very simple, easy to fabricate, operates at low voltage with low power consumption and the displacement can be increased by using longer bimorphs. The thick micropositioner accomplished all required specifications but operates at IOV. This voltage may be obtained from the $3 \mathrm{~V}$ supply voltage. Neverteless, power consumption of a charge pump must be taken into account. On the other hand, thin micropositioner operates at $3 \mathrm{~V}$ achieving similar total displacements, not fulfilling precision requirements. Thinner actuators will achieve larger displacements but show less precision and less mechanical stiffness,

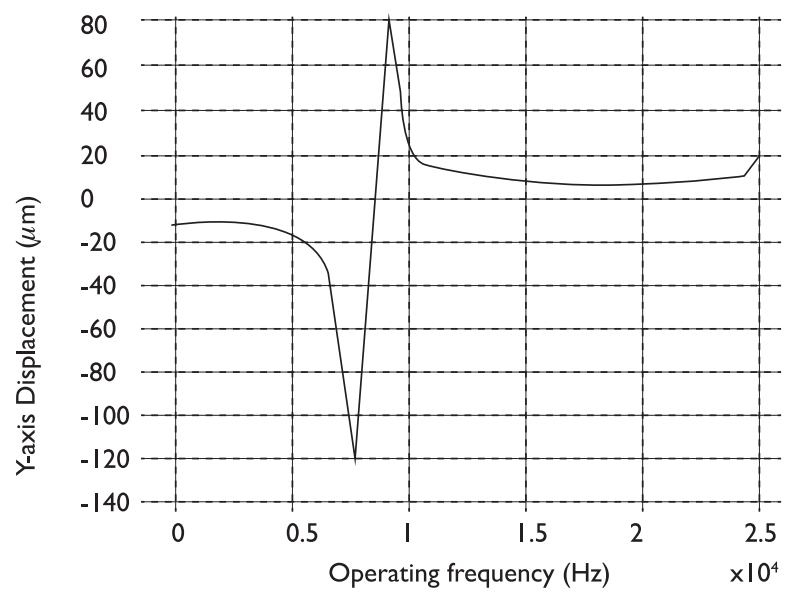

Figure I I. Y-axis displacement vs frequency for the thick micropositioner. 
whereas thicker actuators improve displacements but require higher voltages and thus higher power consumption to obtain the same total displacement. This must be considered in order to implement the microactuators as part of a miniaturized robot.

The resonant frequencies of all actuators were obtained and constitute valuable information to avoid resonance during micropositioning and operate near or at resonance in locomotion and conveyor actuators.

The von Mises analysis provided information on the regions of maximum stress and their stress values. This information allows proper microactuator design to ensure continuous operation for a large number of cycles. Future work includes measurement of the yield stress of the PZT3203HD which is not reported neither in academic literature, nor in datasheets. This experimental parameter will allow to carry out a fatigue analysis, determine the maximum weight load that the microactuator can withstand and compare with the simulated von Mises stress to make sure the actuator's stress is within the acceptable range for this material.

\section{References}

[I] Piefort,V. (2000) Finite Element Modeling of Piezoelectric Active Structures. Tesis. Faculty of Applied Sciences: Université Libre de Bruxelles.

[2 Young] W. C. \& Budynas R. G. (2002) Roark's Formulas for Stress and Strain - 7th edition: McGraw-Hill, International Edition.

[3] CTS Electronic Components (2005). Piezoelectric Constants for 3203HD. CTS Electronic Components, Inc.

[4] CTS Electronic Components. PZT5A \& 5H Materials Technical Data. CTS Electronic Components, Inc. 4800 Alameda Blvd NE.

[5] Gorman, J.J. et al. (2006) Design of an On-Chip MicroScale Nanoassembly System. Proceedings of the $4^{\text {th }}$ International Symposium on Nanomanufacturing, pp. 160-162.

[6] Jensen, Kimberly A. (2003) Analysis And Design of Surface Micromachined Micromanipulators for Out-ofPlane Micropositioning. Department of Mechanical Engineering: Brigham Young University. 